\title{
Endoplasmic reticulum stress response in an INS- 1 pancreatic $\beta$-cell line with inducible expression of a folding-deficient proinsulin
}

\author{
Taila Hartley ${ }^{1,2}$, Madura Siva ${ }^{1,3}$, Elida Lai ${ }^{1,2}$, Tracy Teodoro ${ }^{1,2}$, Liling Zhang ${ }^{1}$, Allen Volchuk ${ }^{1,2,3,4^{*}}$
}

\begin{abstract}
Background: Cells respond to endoplasmic reticulum stress (ER) stress by activating the unfolded protein response. To study the ER stress response in pancreatic $\beta$-cells we developed a model system that allows for pathophysiological ER stress based on the Akita mouse. This mouse strain expresses a mutant insulin 2 gene (C96Y), which prevents normal proinsulin folding causing ER stress and eventual $\beta$-cell apoptosis. A double-stable pancreatic $\beta$-cell line (pTet-ON INS-1) with inducible expression of insulin 2 (C96Y) fused to EGFP was generated to study the ER stress response.

Results: Expression of Ins 2 (C96Y)-EGFP resulted in activation of the ER stress pathways (PERK, IRE1 and ATF6) and caused dilation of the ER. To identify gene expression changes resulting from mutant insulin expression we performed microarray expression profiling and real time PCR experiments. We observed an induction of various ER chaperone, co-chaperone and ER-associated degradation genes after $24 \mathrm{~h}$ and an increase in pro-apoptotic genes (Chop and Trib3) following $48 \mathrm{~h}$ of mutant insulin expression. The latter changes occurred at a time when general apoptosis was detected in the cell population, although the relative amount of cell death was low. Inhibiting the proteasome or depleting Herp protein expression increased mutant insulin levels and enhanced cell apoptosis, indicating that ER-associated degradation is maintaining cell survival.

Conclusions: The inducible mutant insulin expressing cell model has allowed for the identification of the ER stress response in $\beta$-cells and the repertoire of genes/proteins induced is unique to this cell type. ER-associated degradation is essential in maintaining cell survival in cells expressing mutant insulin. This cell model will be useful for the molecular characterization of ER stress-induced genes.
\end{abstract}

\section{Background}

An increase in post-prandial blood glucose stimulates pancreatic $\beta$-cells to secrete insulin, which mediates glucose disposal into tissues such as muscle and fat. Glucose also acutely stimulates insulin translation, which replenishes the $\beta$-cell granules that have been depleted during secretion [1]. The effect of glucose on translation increases the protein folding load in the endoplasmic reticulum (ER) of the $\beta$-cell, which may transiently induce ER stress, a condition in which the folding capacity of the ER is insufficient for the level of newly synthesized secretory proteins and results in the

\footnotetext{
* Correspondence: avolchuk@uhnres.utoronto.ca

'Division of Cellular and Molecular Biology, Toronto General Research Institute, University Health Network, 101 College Street, TMDT 10-706, Toronto, M5G 1L7, Canada
}

accumulation of misfolded proteins. Such conditions are sensed by ER localized stress sensors that mediate the unfolded protein response (UPR) [2]. This results in a transient reduction in translation efficiency to reduce secretory protein load and induces chaperone capacity and ER-associated degradation (ERAD). ER stress is likely a physiological situation the $\beta$-cell transiently experiences following feeding.

ER stress is also a feature of pathological conditions associated with obesity and diabetes. Excess nutrients (free fatty acids, glucose), amyloid deposits and inflammatory cytokines have all been shown to induce ER stress in pancreatic $\beta$-cells [3]. These conditions induce the UPR pathways that attempt to counteract ER stress. However, chronic ER stress can lead to apoptosis induction [4], particularly in cell types with high secretory 
capacity such as the $\beta$-cell. This is evident from the fact that perturbation of the UPR signaling pathways in vivo leads to pancreatic $\beta$-cell death in animal models [5-7] and humans [8] and mutations in the insulin molecule in Akita mice results in ER stress-induced $\beta$-cell apoptosis $[9,10]$. In addition, it has been hypothesized that chronic conditions associated with obesity over time may lead to chronic ER stress-induced $\beta$-cell death and depletion of $\beta$-cell mass that results in type 2 diabetes [11].

Thus, understanding how pancreatic $\beta$-cells deal with, and respond to ER stress, is vital for understanding $\beta$ cell biology under physiological and pathological conditions. A detailed temporal analysis of the ER stress response in $\beta$-cells has not been conducted. In addition the molecular mechanism of ER stress-induced apoptosis is still, for the most part, unclear. As mentioned, expression of folding-deficient proinsulin in the Akita mouse leads to pancreatic $\beta$-cell death as a result of ER stress and apoptosis [9]. Thus, the Akita mouse provides a model of $\beta$-cell dysfunction resulting from ER stress and affords a system to study the ER stress response independently of using commonly used toxins such as thapsigargin or tunicamycin.

To study the ER stress response in pancreatic $\beta$-cells we developed a pancreatic $\beta$-cell culture system based on the Akita mouse. Inducible expression of mutant insulin 2 (C96Y) fused to EGFP [Ins2 (C96Y)-EGFP] caused ER stress and apoptosis. In this study we examined the temporal gene expression response resulting from induction of Ins2 (C96Y)-EGFP expression in INS$1 \beta$-cells and the role of ERAD in mediating cell survival.

\section{Methods}

Cloning of the pTRE-Tight Insulin 2 (C96Y)-EGFP construct Full-length wild-type mouse insulin 2 cDNA was amplified by PCR from pIns2 (WT)-EGFP, a fusion construct obtained from Dr. Seiichi Oyadomari (New York University School of Medicine) [12]. The PCR fragment was cloned into pCRII-TOPO vector (Invitrogen). Using the QuikChange II XL Site-Directed Mutagenesis kit (Stratagene), a C96Y mutation was introduced into the insulin 2 cDNA. The mutation was confirmed by DNA sequencing. Ins2 (C96Y) was cloned into the pEGFP-N1 vector (BD Biosciences), the stop codon was removed and the resulting fusion construct pIns2 (C96Y)-EGFP was cloned into the NheI/NotI site of a pTRE-Tight vector (Clontech).

\section{Generation of an inducible Insulin 2 (C96Y)-EGFP expressing INS- $1 \beta$-cell line}

Initially a stable pTet-ON INS- 1 clone was generated by transfecting INS-1 cells (obtained from Dr. Claes
Wollheim, University of Geneva) [13] with the pTet-ON plasmid and stable clones were selected following the protocol provided (Clontech). Several clones were isolated and tested by transient transfection using a luciferase reporter assay and the clone with the lowest basal expression and highest doxycyline induction (INS1 pTet-ON \#46) was used for generation of the double stable cell line.

Double-stable Ins2 (C96Y)-EGFP expressing cells were generated by co-transfection with a hygromycin resistance plasmid and the pTRE -Ins2 (C96Y)-EGFP plasmid into pTet-ON INS-1 \#46 cells and selection by addition of antibiotics: $200 \mu \mathrm{g} / \mathrm{ml}$ geneticin and $50 \mu \mathrm{g} / \mathrm{ml}$ hygromycin B (Invitrogen). Individual clones were isolated and tested for Ins2 (C96Y)-EGFP expression by western blotting and immunofluorescence before and after induction with doxycycline $(2 \mu \mathrm{g} / \mathrm{ml})$ for $24 \mathrm{~h}$. A positive clone was identified and fluorescence-activated cell sorting was used to isolate the highest 20\% of EGFP-positive cells in this clonal population after induction with doxycycline for $48 \mathrm{~h}$. The cells were expanded in media without doxycycline and referred to as clone \#4S2.

Clone \#4S2 cells were maintained in RPMI 1640 (11.1 $\mathrm{mM}$ glucose, $1 \mathrm{mM}$ sodium pyruvate, $10 \mathrm{mM}$ HEPES) supplemented with $10 \%$ fetal bovine serum, $2 \mathrm{mM}$ Lglutamine, $55 \mu \mathrm{M} \beta$-mercaptoethanol with antibiotics (100 units $/ \mathrm{ml}$ penicillin and $100 \mu \mathrm{g} / \mathrm{ml}$ streptomycin) and selection drugs $(200 \mu \mathrm{g} / \mathrm{ml} \mathrm{G} 418$ and $50 \mu \mathrm{g} / \mathrm{ml}$ hygromycin).

\section{Cell lysis and western blot analysis}

Cells were washed in PBS and lysed in ice-cold lysis buffer (1\% Triton X-100, $20 \mathrm{mM}$ HEPES, $\mathrm{pH}$ 7.4, $100 \mathrm{mM}$ $\mathrm{KCl}, 2 \mathrm{mM}$ EDTA, $1 \mathrm{mM}$ PMSF, $10 \mu \mathrm{g} / \mathrm{ml}$ leupeptin, and $10 \mu \mathrm{g} / \mathrm{ml}$ aprotinin, $10 \mathrm{mM} \mathrm{NaF}, 2 \mathrm{mM} \mathrm{Na}_{3} \mathrm{VO}_{4}$, and $10 \mathrm{nM}$ okadaic acid) for 15-20 min on ice. Lysates were centrifuged at $13,000 \mathrm{rpm}$ for $10 \mathrm{~min}$ at $4^{\circ} \mathrm{C}$ and the protein concentration in the supernatant was determined using the BCA protein assay (Pierce). Equal amounts of protein were resolved by SDS-PAGE and immunoblotted as described previously [14]. For detection of insulin and cleaved caspase- 3 by immunoblotting, the samples were resolved using 4-12\% NuPAGE gels (Invitrogen). The following primary antibodies were used: Phospho-eIF2 $\alpha$ (Cell Signaling, \#9721), GADD153/CHOP (Santa Cruz, sc-575), KDEL (StressGen, SPA-827), insulin (Santa Cruz, sc-9168), insulin (Dako, A0564), $\gamma$-tubulin (Sigma, T6557), polyclonal anti-GFP (obtained from Dr. James E. Rothman, Yale University), monoclonal anti-GFP (Clontech, 632381), cleaved caspase 3 (Cell Signaling, \#9661S), ubiquitin (Dako, Z0458), GM130 (Transduction Laboratories, G65120), Hsp90 (Transduction Laboratories, 610418). The polyclonal Herp antibody was provided by Dr. 
Linda Hendershot (St. Jude Children's Hospital, Memphis, TN).

\section{Fluorescence microscopy}

Cells were treated as described in the figure legends, washed with PBS and fixed with $4 \%$ paraformaldehyde in PBS for 20 minutes, washed with PBS and mounted on glass coverslips using Fluoromount G (EM Sciences). GFP fluorescence was visualized with a Zeiss laser scanning confocal microscope. Clone \#4S2 INS-1 cells were treated as described in the figure legend, washed with PBS and fixed with 4\% paraformaldehyde in PBS for 20 minutes. The samples were processed for immunofluorescence microscopy as reported previously [15] and immunostained with anti-ATF6 (TO13/14) antibody at a 1:100 dilution [14]. Quantitation of ATF6 staining in the nucleus (marked by DAPI staining) was measured using ImageJ Software. The average intensity in arbitrary units in the nuclear area was determined. A minimum of 18 cells for all experimental condition were quantified and the mean relative nuclear intensity is reported.

\section{Cell Fractionation}

Following doxycycline treatment for 72 hours, clone \#4S2 cells were washed with PBS and resuspended in homogenization buffer: (0.25 M Sucrose, $4 \mathrm{mM}$ HEPES, $1 \mathrm{mM} \mathrm{MgCl} 2,1.5 \mathrm{mM}$ EDTA containing a complete protease inhibitor tablet (Roche), $1 \mathrm{mM}$ PMSF, $10 \mathrm{mM}$ $\mathrm{NaF}, 2 \mathrm{mM} \mathrm{Na} \mathrm{VO}_{4}, 10 \mathrm{nM}$ okadaic acid). Cells were homogenized on ice with 12 strokes using a ball-bearing cell homogenizer. The resulting homogenate was either centrifuged at $100000 \times \mathrm{g}$ for $1.5 \mathrm{~h}$ to generate membrane (pellet) and cytosol (SN) fractions, or subjected to a $0.45 \mathrm{M}$ to $2 \mathrm{M}$ sucrose gradient for $18 \mathrm{~h}$ at 30000 $\mathrm{rpm}, 4^{\circ} \mathrm{C}$ as outlined in [16]. After ultracentrifugation, $0.5 \mathrm{ml}$ fractions were taken from the top of the gradient.

\section{Electron Microscopy}

Clone \#4S2 cells were fixed in 2\% glutaraldehyde (EM Sciences) in $0.15 \mathrm{M}$ Sorensen's Phosphate Buffer (pH 7.4) (EM Sciences) for $30 \mathrm{~min}$ at room temperature. The cells were washed twice with PBS and collected into new tubes. Samples were prepared for transmission electron microscopy by the electron microscopy facility at Mount Sinai Hospital (Toronto). Briefly, the cell pellets were fixed in $2 \%$ glutaraldehyde in $0.1 \mathrm{M}$ sodium cacodylate buffer ( $\mathrm{pH}$ 7.3) for $2 \mathrm{~h}$, rinsed with the same buffer for $10 \mathrm{~min}$, and post-fixed for $1.5 \mathrm{~h}$ in $1 \% \mathrm{OsO}_{4}$. After rinsing with the same buffer for $10 \mathrm{~min}$, the cells were dehydrated through a graded ethanol series up to $100 \%$ ethanol. The cells were then embedded in Spurr resin in an oven at $65^{\circ} \mathrm{C}$ overnight. Thin sections $(\sim 100$ $\mathrm{nm}$ ) were cut with an RMC MT6000 ultramicrotome. The sections were placed on copper grids and stained with uranyl acetate $(20 \mathrm{~min})$ and lead citrate (10 min). The grids were examined in a FEI Tecnai 20 transmission electron microscope and images were captured using a Gatan Dualview digital camera.

\section{RNA isolation and real-time PCR analysis}

For real-time PCR analysis, total RNA was isolated from cells untreated or treated with $2 \mu \mathrm{g} / \mathrm{ml}$ doxycycline for the indicated times using TRIzol Reagent (Invitrogen) followed by purification with RNeasy Mini Kit (Qiagen). Total RNA was reverse transcribed to single-stranded cDNA using the High-Capacity cDNA Reverse Transcription Kit (Applied Biosystems). The resulting cDNA was used for real-time PCR analysis by the TaqMan Gene Expression system (Applied Biosystems) as described previously [14]. The following primers were obtained from Applied Biosystems: Chop (Rn00492098_g1), Atf4 (Rn00824644_g1), Grp78 (Rn00565250_m1), Pdi

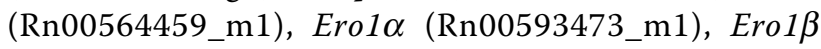
(Rn01520960_m1), Sel1 (Rn00710081_m1), Erdj4 (Rn00562259_m1), Erdj5 (Rn01486444_m1), $\beta$-actin (4352931E).

\section{XBP1 splicing assay}

Total RNA was isolated and rat XBP-1 cDNA was amplified by RT-PCR (QIAGEN OneStep RT-PCR kit) using primers that flank the intron excised by IRE1 exonuclease activity as described previously [14].

\section{siRNA transfection}

Clone \#4S2 cells were reverse transfected using Lipofectamine RNAiMAX with $10 \mathrm{nM}$ Herp siRNA (Invitrogen) or a control siRNA (directed to bacterial $\beta$-galactosidase) as described previously [17]. Twenty-four hours later the cells were incubated or not with doxycycline for $48 \mathrm{~h}$ then either lysed for western blot analysis or for measurement of apoptosis using the cell death ELISA kit (Roche).

\section{Apoptosis assays}

Cell apoptosis was measured using the cell death detection ELISA kit (Roche) according to the instructions provided in the kit. Briefly, clone \#4S2 cells were seeded in 24-well plates (200 000 cells/well) and treated as indicated in the figure legends. Following the treatments, the cells were lysed and oligonucleosomes in the cytoplasm (indicative of apoptosis-associated DNA degradation) were quantified according to the manufacturer's instructions.

Terminal deoxynucleotidyl transferase-mediated dUTP nick-end labeling (TUNEL) assays were performed using the APO-BrdU TUNEL Assay Kit (Invitrogen). Clone \#4S2 cells were treated as described in the figure legend, washed with warm PBS, trypsinized, then stained with Fluor-647 dye-labeled anti-BrdU antibody, as described by 
the manufacturer's instructions. After staining, the samples were analyzed in a FACSCalibur flow cytometer (Becton Dickinson). To standardize each sample and set the quandrants, a negative control (INS-1 cells) and a positive control (provided by the APO-BrdU TUNEL assay kit) were used. GFP and the Fluor-647 dye-labeled anti-BrdU antibody were excited using the FL1 (530/30) and FL4 $(661 / 16)$ lasers, respectively.

\section{Microarray analysis}

Microarray expression profiling was used to assess the global transcriptional changes in response to Ins2 (C96Y)-EGFP expression in clone \#4S2 cells. Cells were induced or not with doxycycline for $24 \mathrm{~h}, 48 \mathrm{~h}$ or 5 days and total RNA was isolated using TRIzol Reagent (Invitrogen) followed by isolation using an RNeasy Mini Kit (Qiagen). Assessment of RNA quality and microarray analysis was performed at the University Health Network (Toronto) microarray centre. Briefly, following RNA quality assessment with an Agilent BioAnalyzer, samples were reverse transcribed to cDNA. cDNA was purified with a cDNA purification module from Affymetrix. Biotin was incorporated during in vitro transcription and purified cRNA was then fragmented with a chemical reaction. $15 \mu \mathrm{g}$ of labeled and fragmented cRNA was hybridized to Rat Genome 2302.0 arrays (Affymetrix Genechip) for $17 \mathrm{~h}$ at $45^{\circ} \mathrm{C}$ at $60 \mathrm{rpm}$. The arrays were stained and washed using fluidic stations with antibody and streptavidin phycoerythrin conjugate solutions. All arrays are scanned using an Affymetrix $30007 \mathrm{G}$ scanner. The data sets were analyzed using GeneSpring software (Version 7.1) (Agilent Technologies) and statistical analysis was performed using GeneSpring software according to the manufacturer's specifications. Genes with a minimum 2-fold difference between control and doxycycline-treated cells in at least two independent experiments at $24 \mathrm{~h}, 48 \mathrm{~h}$ and 5 days are listed in the Additional file 1 and Additional file 2. The raw microarray data has been deposited in the Gene Expression Omnibus (GEO) database (GSE22537).

\section{Data analysis}

Results are presented as mean \pm SE. Statistical significance between two experimental conditions was analyzed using a two-sample $t$-test assuming equal variance. Data from several or more groups was analyzed by ANOVA, followed by Tukey post hoc test. $\mathrm{P}<0.05$ was considered statistically significant.

\section{Results}

Generation and characterization of the Insulin 2 (C96Y)EGFP stable INS-1 cell line

We first generated a stable pTet-ON INS-1 cell line that allows for doxycycline-inducible protein expression. The cell line was tested by transient transfection of the Ins2 (C96Y)-EGFP fusion construct in the presence or absence of doxycycline. Fusion protein expression was monitored by western blotting and fluorescence microscopy. Expression of the fusion protein was doxycylinedependent and the fusion protein was excluded from the nucleus and localized throughout the cell (Figure $1 \mathrm{~A}, \mathrm{~B})$. Interestingly, the expression of this construct also resulted in the production of a lower migrating band, which may be due to proteolytic cleavage of the fusion construct in the cell (Figure 1A, arrow). A stable Ins2 (C96Y)-EGFP pTet-ON cell line was generated by co-transfection with a hygromycin resistance plasmid. We isolated a clone with inducible mutant insulin expression and fluorescence-activated cell sorting was used to isolate EGFP-positive cells (top 20\%) after $48 \mathrm{~h}$ of doxycycline induction. The sorted cells (designated clone \#4S2) was expanded in media without doxycycline. This clone exhibited low basal Ins2(C96Y)-EGFP expression and a marked induction following doxycycline treatment (Figure 1C, D).

In addition to the full-length fusion protein other GFP immunoreactive bands were observed in both TX-100 detergent whole cell lysates or lysates prepared by direct lysis of the cells in SDS sample buffer (Figure 2A). These fragments are likely degradation products of the full-length fusion protein and most of the fragments could not be efficiently immunoprecipitated using an anti-GFP antibody (Figure 2B). Cells were homogenized and subjected to membrane and cytosol fractionation. Whereas the full-length Ins2 (C96Y)-EGFP fusion protein could be detected in the membrane fraction, the degradation fragments were present exclusively in the cytosol fraction (Figure 2C). The full-length fusion protein was detected in ER fractions by sucrose density fractionation while the lower migrating degradation fragments were present exclusively in the cytosol fractions (Figure 2D). Since no degradation fragments were present in microsome fractions it is likely that degradation of the full-length fusion protein occurs in the cytosol. The presence of some soluble ER lumenal GRP78 (and Ins2 (C96Y)-EGFP) in cytosolic fractions in the sucrose gradient may be due to some leakage during cell homogenization.

We examined the morphology of the stable cell line by electron microscopy before and after doxycycline induction. In non-induced cells a normal ER morphology was observed (Figure 3A, B), whereas cells expressing Ins2 (C96Y)-EGFP for three days had an altered ER morphology (Figure 3C, D). The ER was expanded and dilated compared to control cells. The ER tended to be even more severely dilated in many of the cells after six days of mutant insulin expression (Figure 3E, F). This morphology is characteristic of unfolded protein accumulation and ER 
A

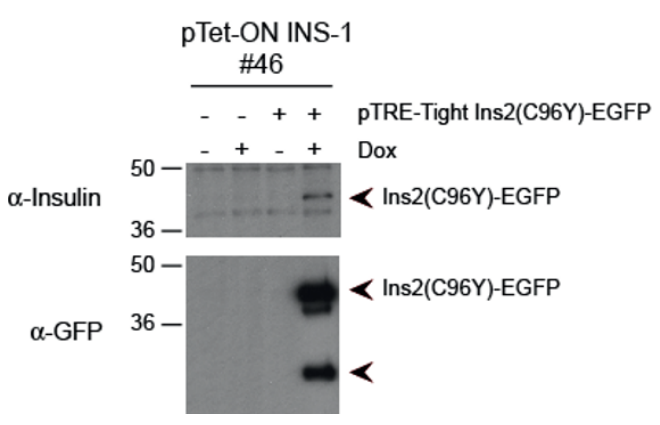

C

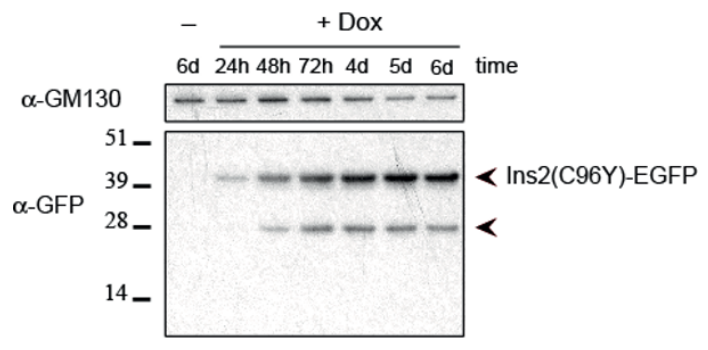

D

No Dox (6d)

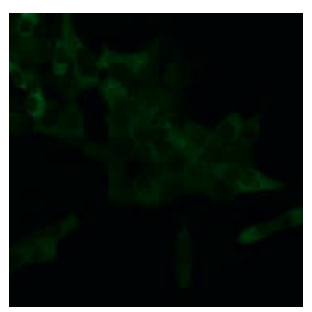

$24 h$
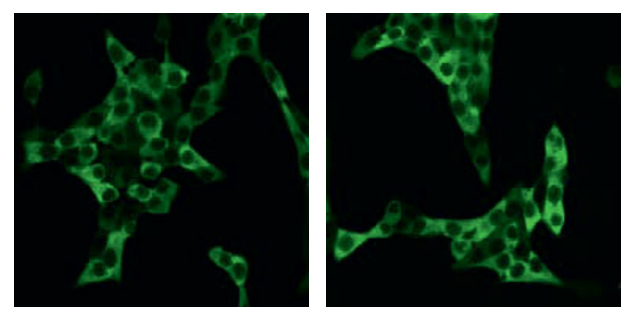

$3 d$

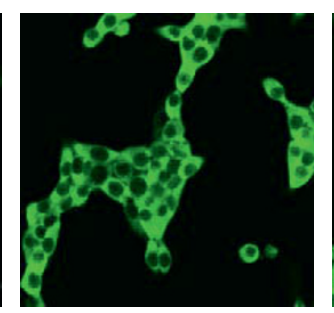

+ Dox
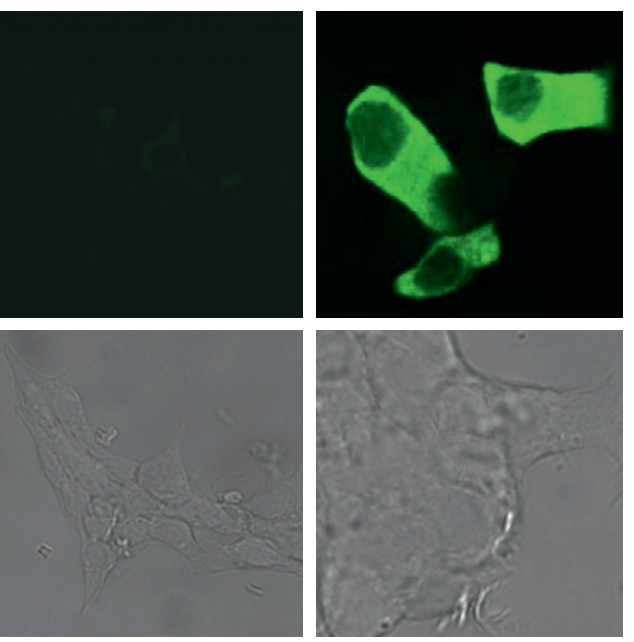

6d

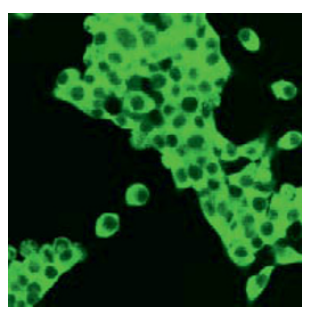

Figure 1 Induction of insulin 2 (C96Y)-EGFP protein expression in pTet-ON INS-1 cells by doxycyline. A-B. pTet-ON INS-1 \#46 cells were transiently transfected with pTRE-Tight Ins2 (C96Y)-EGFP construct in the presence or absence of $2 \mu \mathrm{g} / \mathrm{ml}$ doxycycline (Dox) for $48 \mathrm{~h}$. In (A), cells were washed in PBS, lysed and $10 \mu \mathrm{g}$ of protein were resolved by SDS-PAGE and immunoblotted using antibodies to insulin and GFP. In (B) the cells were washed in PBS, fixed and mounted. GFP fluorescence was visualized using a laser confocal fluorescence microscope. C-D. A stable Ins2 (C96Y)-EGFP expressing INS1 clone (Clone \#4S2), generated as described in the methods, was untreated (-Dox) or treated with $2 \mu \mathrm{g} / \mathrm{ml}$ doxycycline (+Dox) for the times indicated. The cells were washed in PBS, lysed and an equal amount of protein per condition were resolved by SDS-PAGE and immunoblotted using antibodies to GM130 and GFP (C). In (D), EGFP fluorescence in fixed cells was visualized by confocal fluorescence microscopy.

stress [2] and has been observed in $\beta$-cells of the Akita mouse [9]. In addition, apoptotic cells were observed in the population expressing the fusion protein (Figure 3C, arrowheads).

\section{The ER stress response to Insulin 2 (C96Y)-EGFP expression}

The morphological analysis indicated that the expression of Ins2 (C96Y)-EGFP was causing an accumulation of this protein in the ER and causing ER stress. We thus examined whether doxycycline-induced expression of Ins2 (C96Y)-EGFP was activating UPR signaling pathways. Ins2 (C96Y)-EGFP expression was induced for various times and activation of the ER stress-sensing pathways was monitored. Spliced XBP-1, indicative of IRE $1 \alpha$ activation, was detected after $24 \mathrm{~h}$ of doxycyline induction and similar levels of spliced XBP-1 were present throughout the induction period for up to 7 days (Figure 4A, shows a representative example up to 5 days of induction). The levels of phospho-eIF2 $\alpha$, indicative of PERK activation, were also increased (Figure 4B), as were the levels of active ATF6-p50 (Figure 4C). Thus, expression of the mutant insulin causes measurable activation of the ER stress pathways mediated by IRE1 $\alpha$, PERK and ATF6.

To examine the global transcriptional response to mutant insulin expression we performed microarray analysis of the gene expression changes following Ins2 


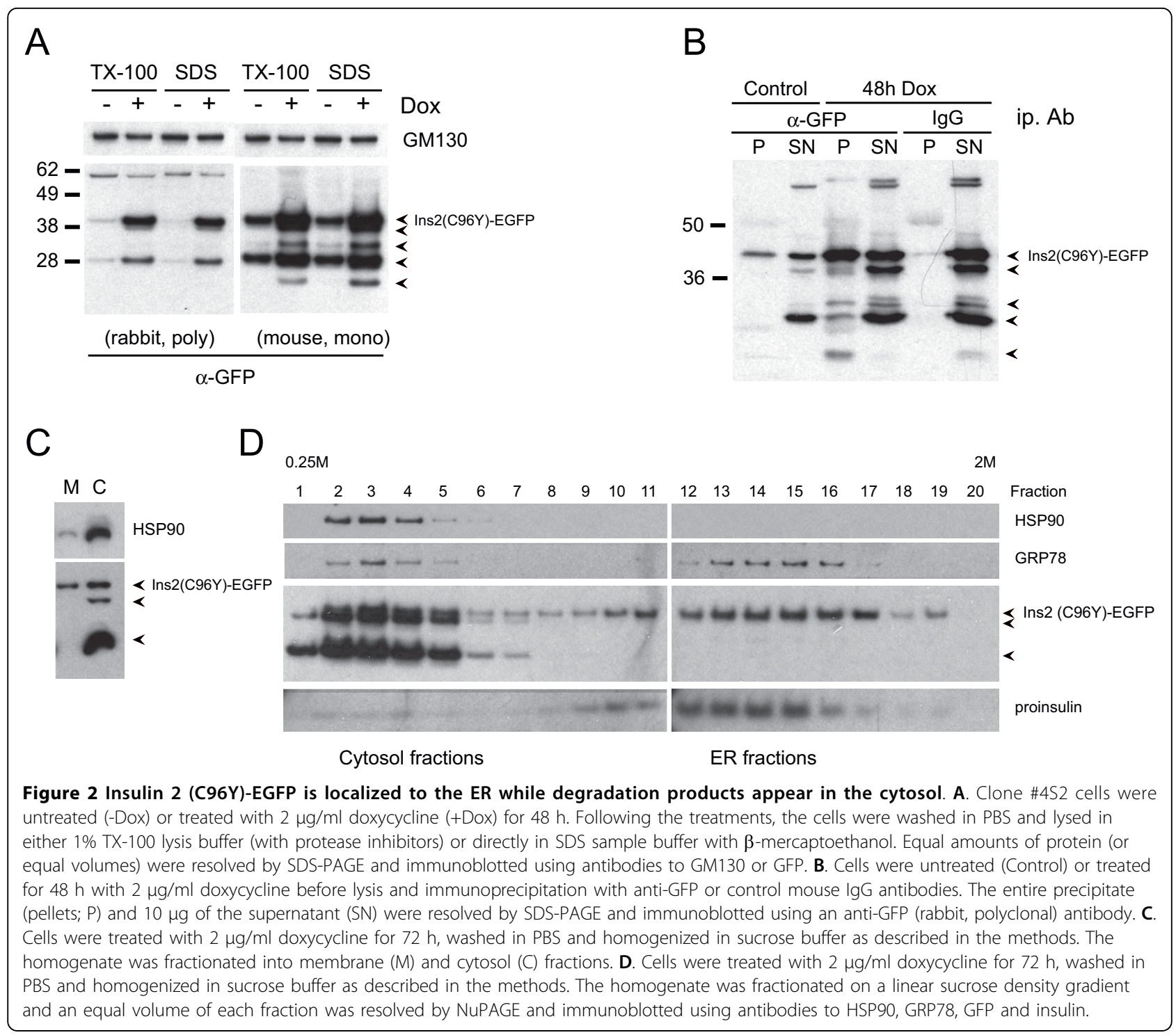

(C96Y)-EGFP expression. Total RNA was prepared after $24 \mathrm{~h}, 48 \mathrm{~h}$ and 5 days of doxycycline treatment from three independent experiments, reverse transcribed and hybridized to Affymetrix rat genome arrays. Gene expression changes were examined and those that were upregulated or downregulated by 2-fold after doxycyline-induced expression of Ins2 (C96Y)-EGFP are listed in the Additional files 1 and 2. Following $24 \mathrm{~h}$ induction 45 genes were upregulated and 5 were downregulated. After $48 \mathrm{~h}$ induction 86 genes were upregulated and 37 downregulated, whereas 68 genes were induced and 56 reduced after 5 days induction. These numbers include genes (both well-substantiated and transcribed loci) that were identified as statistically significant in at least two of three experiments.

Shown in Table 1 are a selected list of genes induced $>2$-fold in at least two independent experiments at the various time points. This list includes genes involved in the UPR response, protein folding and modification, ERAD and protein transport. Several patterns emerged from this analysis. After $24 \mathrm{~h}$ of mutant protein expression, the majority of the genes induced were ER localized chaperone genes (Erdj4/Dnajb9, P58 ${ }^{I P K} /$ Dnajc3, Erdj3/Dnajb11, Fkbp11) as well as the ERAD-associated genes (Herp and Sel1). The Sdf2l1 gene was the most abundantly induced gene present in all three experiments. In addition, the Atf4 and Chop transcription factors, target genes of the PERK-eIF2 $\alpha$ pathway, were also induced in two out of three experiments at this early time point. Trib3 (Trb3), a putative target gene of the CHOP transcription factor [18], was also induced in two out of three experiments.

Following $48 \mathrm{~h}$ of mutant protein expression a greater number of genes were induced compared to $24 \mathrm{~h}$ (Table 

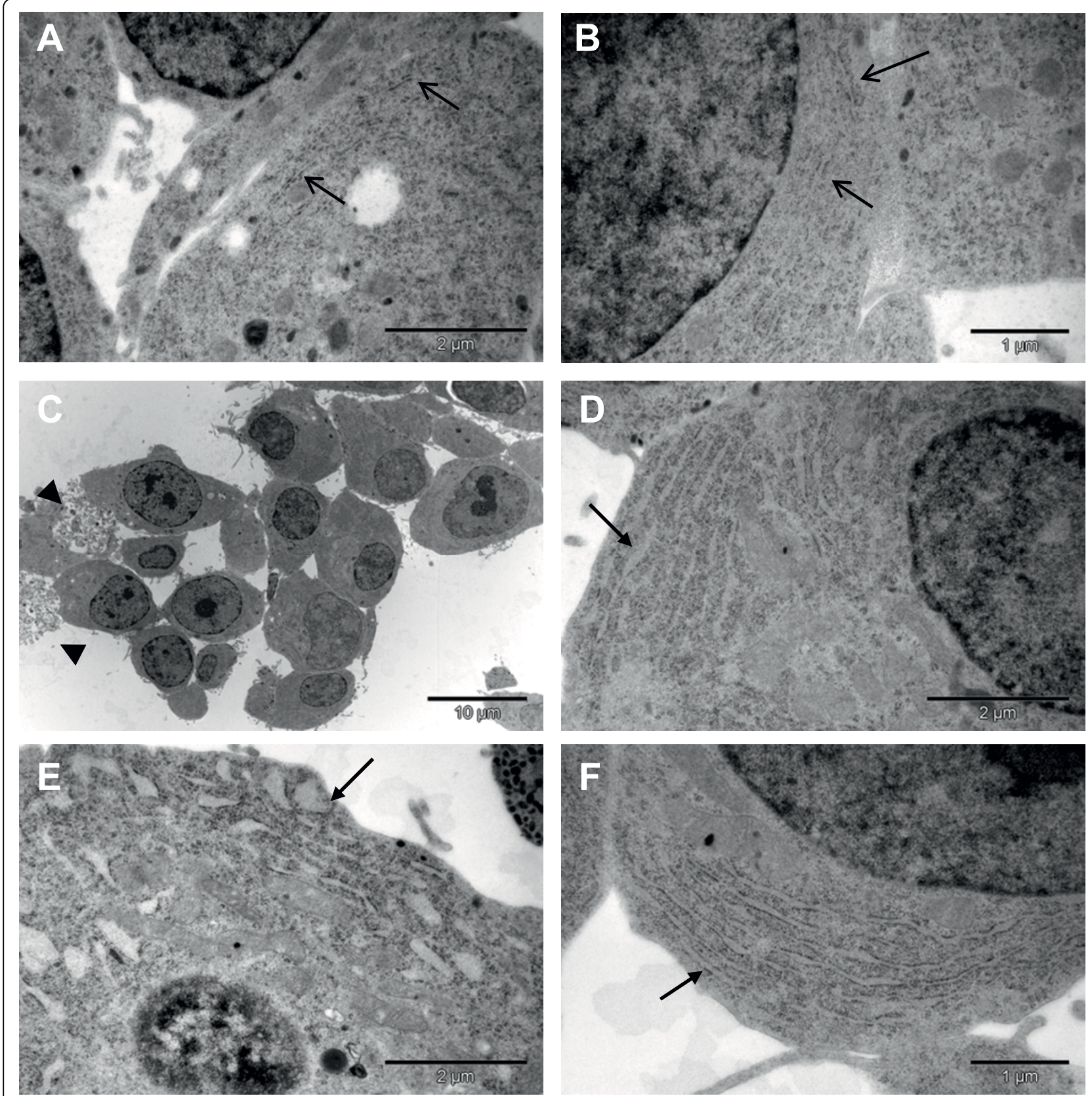

Figure 3 Effect of insulin 2 (C96Y)-EGFP expression on ER morphology. Clone \#4S2 cells untreated (A, B) or treated with $2 \mu \mathrm{g} / \mathrm{ml}$ doxycycline for 3 days (C, D) or 6 days (E, F) were washed in PBS and fixed. The cells were processed for transmission electron microscopy as described in the methods. ER structures in uninduced cells (A, B, arrows), and distended ER structures in mutant insulin expressing cells following doxycyline-induction (D-F, arrows) are indicated. The presence of apoptotic cells was evident in doxycyline-induced cells (C, arrowheads).

1 and Additional files 1 and 2). Additional chaperone genes (Pdia2, Pdia 3 and Pdia4) were upregulated. The levels of the Chop transcription factor were also significantly higher than at the $24 \mathrm{~h}$ time point. However, the most abundantly induced gene at $48 \mathrm{~h}$ of mutant protein expression was Trib3 ( $T r b 3$ ), a gene whose protein product has been implicated in apoptosis among other cellular processes $[18,19]$. At this time point other genes including protein transport genes and transcription factors were also upregulated. By 5 days of mutant protein expression the gene expression changes as monitored by microarray was more variable between experiments than at the $48 \mathrm{~h}$ time point. However, all the chaperone genes observed at earlier time points were still elevated and additional PDI family member genes (Pdia6 and Txndc4) were induced. The levels of Trib3 were lower 


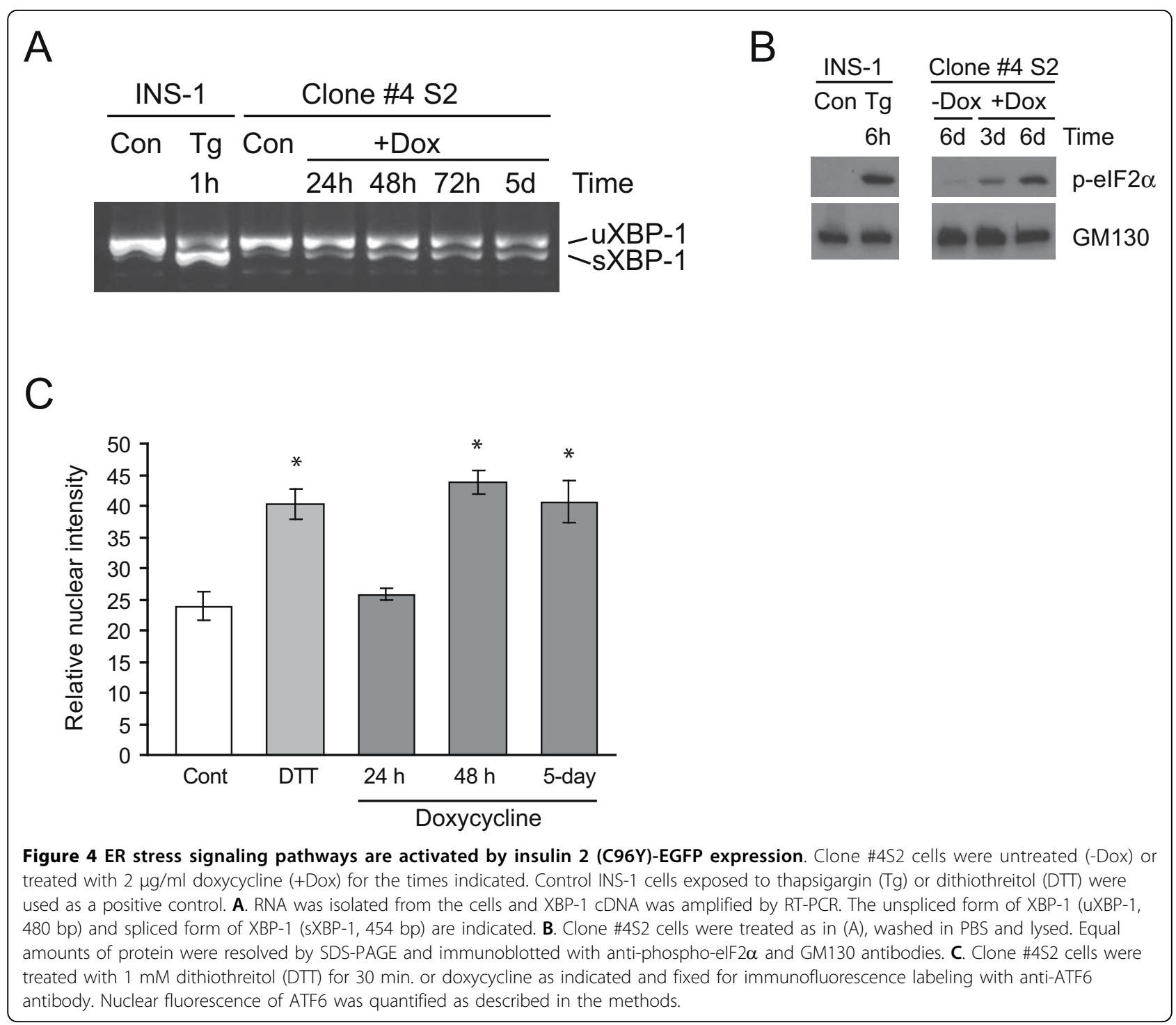

compared to the $48 \mathrm{~h}$ time point, but still elevated. Interestingly, the levels of Sdf2l1, Creld 2 and Armet remained highly induced throughout the time course of mutant protein expression.

Although some of the gene expression changes found were expected based on the ER stress response induced in other models (discussed later), some genes predicted to be increased were not observed, such as the ER chaperone genes Grp78 and Pdi. Microarray expression profiling can lead to false negatives due to inefficient probes. We therefore examined the mRNA and protein levels of several well established targets of the UPR by real-time PCR and western blotting. An increase in the mRNA levels of Grp78, Pdi, Chop and Sel1 was observed in response to doxycycline-induced mutant insulin expression (Figure 5A-D). The latter two changes substantiate the microarray results. However, both
Grp78 and Pdi are significantly upregulated early (within 24-48 h) of mutant insulin expression. This was not detected by microarray, which does produce false negative results in this case. Consistent with the gene expression data, GRP78 and CHOP protein levels were also induced by Ins2 (C96Y)-EGFP expression (Figure 5E-F). Interestingly, thapsigargin treatment for $6 \mathrm{~h}$ induced higher expression of $\mathrm{CHOP}$ protein in clone \#4S2 than in parental INS-1 cells, suggesting that clone \#4S2 are more susceptible to ER stress (Figure 5F).

We performed additional real-time PCR analysis of other putative ER stress response genes to validate some of the microarray results (Figure 6). Consistent with the microarray data (Table 1) we observed an induction of Erdj4, but not the related gene Erdj5/Dnajc10, despite the fact that the latter has been shown to be induced by ER stress in other cell types [20,21]. In addition, 
Table 1 Selected list of induced genes comparing uninduced cells to cells expressing insulin 2 (C96Y)-EGFP for 24 h, $48 \mathrm{~h}$ and 5 days identified by Affymetrix rat genome arrays

\begin{tabular}{|c|c|c|c|c|c|}
\hline \multirow[t]{2}{*}{ Gene Name } & \multirow[t]{2}{*}{ Entrez Gene ID } & \multirow[t]{2}{*}{ Putative Function } & \multicolumn{3}{|c|}{ Fold Change } \\
\hline & & & $24 \mathrm{~h}$ & $48 \mathrm{~h}$ & $5 d$ \\
\hline \multicolumn{6}{|c|}{ Protein modification/folding } \\
\hline$S d f 2 / 1$ & 680945 & O-mannosylation? & 5.7 & 4.7 & 10.9 \\
\hline Fkbp 11 & 300211 & Peptidyl-prolyl isomerase & 2.9 & 3.9 & 4.3 \\
\hline Dnajb9/Erdj4 & 24908 & Protein folding & 2.5 & 3 & 3.1 \\
\hline Dnajc3/P58 $8^{I P K}$ & 63880 & Protein folding & 2.3 & 2.8 & 4.2 \\
\hline Dnajb11/Erdj3 & 360734 & Protein folding & 2.2 & 2.4 & 3 \\
\hline Pdia2 & 287164 & PDI family, isomerase & & 3.1 & 2.7 \\
\hline Pdia3/Erp57 & 29468 & PDI family, isomerase & & 3.2 & 3.2 \\
\hline Pdia4/Erp72 & 116598 & PDI family, isomerase & & 3.1 & 3.1 \\
\hline Hspa5/Grp78 & 25617 & ER Protein folding & & & 2.6 \\
\hline Pdia6/P5 & 286906 & PDI family, isomerase & & & 3 \\
\hline Txndc4/Erp44 & 298066 & PDI family, isomerase & & & 2 \\
\hline \multicolumn{6}{|c|}{ ER stress-inducible } \\
\hline Herp & 85430 & ERAD & 3.3 & 4.3 & 3.5 \\
\hline Selih & 314352 & ERAD & 2.5 & 2.7 & 2.6 \\
\hline Atf4 & 79255 & Transcription factor & 2.7 & 3 & \\
\hline Chop/Gadd153 & 29467 & Transcription factor & 2.5 & 3.5 & 2.7 \\
\hline Trib3/Trb3 & 246273 & & 11.5 & 19.8 & 6.7 \\
\hline \multicolumn{6}{|c|}{ Transcription factors } \\
\hline Mist1 & 25334 & Transcription factor & 2.9 & 3.2 & 3.7 \\
\hline Atf5 & 282840 & Transcription factor & 2.4 & 3.3 & \\
\hline \multicolumn{6}{|c|}{ Protein transport } \\
\hline Kdelr3 & 315131 & Vesicle transport & 2.1 & 2.9 & 3.8 \\
\hline Tmed3 & 300888 & Vesicle transport & & 2.4 & 2.8 \\
\hline \multicolumn{6}{|c|}{ Selected others } \\
\hline Creld2 & 362978 & ER Protein folding? & 3.6 & 3.6 & 7 \\
\hline Armet & 315989 & & 2.8 & 2.8 & 3.9 \\
\hline Myolg & 289785 & Motor protein & 2.3 & 2.9 & 2.5 \\
\hline El/3 & 296102 & RNA polymerase II-like 3 & 2.1 & 2.2 & 3.6 \\
\hline Magt1 & 116967 & Magnesium transporter & 2.1 & 2.3 & 2.4 \\
\hline Oat & 64313 & Ornithine aminotransferase & 2 & 2.3 & 2.8 \\
\hline
\end{tabular}

Mean fold change from three independent experiments for each time point is shown. Bold indicates the gene was induced in at least 2 independent experiments and italics indicates average induction value of multiple probes for the same gene.

although not detected by microarray, we observed induction of Ero1 $\beta$, but not Ero1 $\alpha$ (Figure 6C, D). The former, but not the latter, has been reported to be ER stress-inducible, which is consistent with our results [22]. It is important to note that doxycyline at the same concentration used in these studies added to a parental INS-1 cell line does not induce any changes in Grp78 or Chop mRNA or protein levels (results not shown), indicating that the changes observed are due to Ins2 (C96Y)-EGFP expression and not the small molecule.

Overall, the microarray and real-time PCR results show that Ins2 (C96Y)-EGFP expression causes the induction of many established ER stress response genes, although there is clearly some selectivity in the genes induced.

\section{Induction of apoptosis following Insulin 2 (C96Y)-EGFP expression}

As shown in Table 1, genes associated with apoptosis such as Chop and Trib3 were already upregulated after $24 \mathrm{~h}$ of mutant insulin expression and the expression levels were even greater after $48 \mathrm{~h}$. We thus examined whether doxycycline-induced expression of Ins2 (C96Y)EGFP induces apoptosis. By light microscopy many of the cells appear rounded in comparison to the control cells at about $72 \mathrm{~h}$ of mutant protein expression, indicative of dead or dying cells (Figure 7A, arrows). To confirm that cell death was due to apoptosis we measured cytoplasmic DNA-associated histone complexes using a sensitive ELISA assay and found that $48 \mathrm{~h}$ to 7 -day treatment of doxycycline causes apoptosis in a time- 


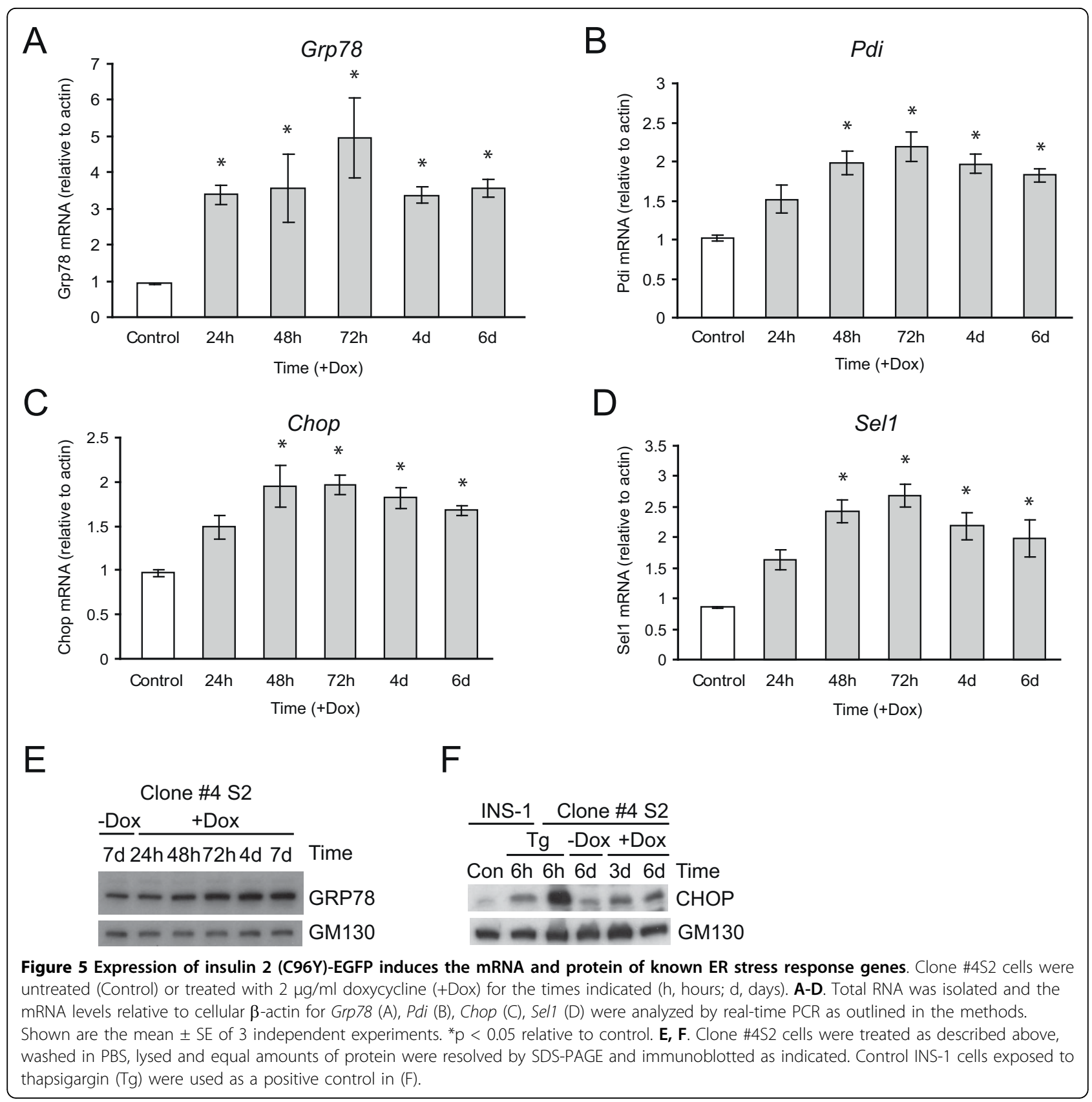

dependent manner (Figure 7B). Western blot analysis also revealed a detectable increase in cleaved caspase- 3 by $\sim 3$ days of mutant protein expression (Figure $7 \mathrm{C}$ ). To identify the relative percentage of apoptotic cells in the mutant insulin expressing population we monitored apoptosis by TUNEL assay using FACS analysis, which also allowed for the detection of mutant protein expression by the GFP fluorescence. Addition of doxycycline increased GFP fluorescence depicted on the y-axis, compared to control cells not treated with doxycycline (Figure 7D). The percentage of apoptotic (TUNEL positive) cells is low and comparable to control cells following 24 $\mathrm{h}$ doxycycline induction (Figure 7D, left panels). However, mutant protein expression following 5 days of doxycycline treatment leads to the induction of apoptosis in approximately $14 \%$ of the population (Figure 7D, right panel).

The extent of apoptosis observed in the population expressing Ins2 (C96Y)-EGFP even for extended periods ( $>5$ days) seemed rather low. We hypothesized that the ER stress response in these cells, particularly the induction of ERAD genes, might be responsible for 


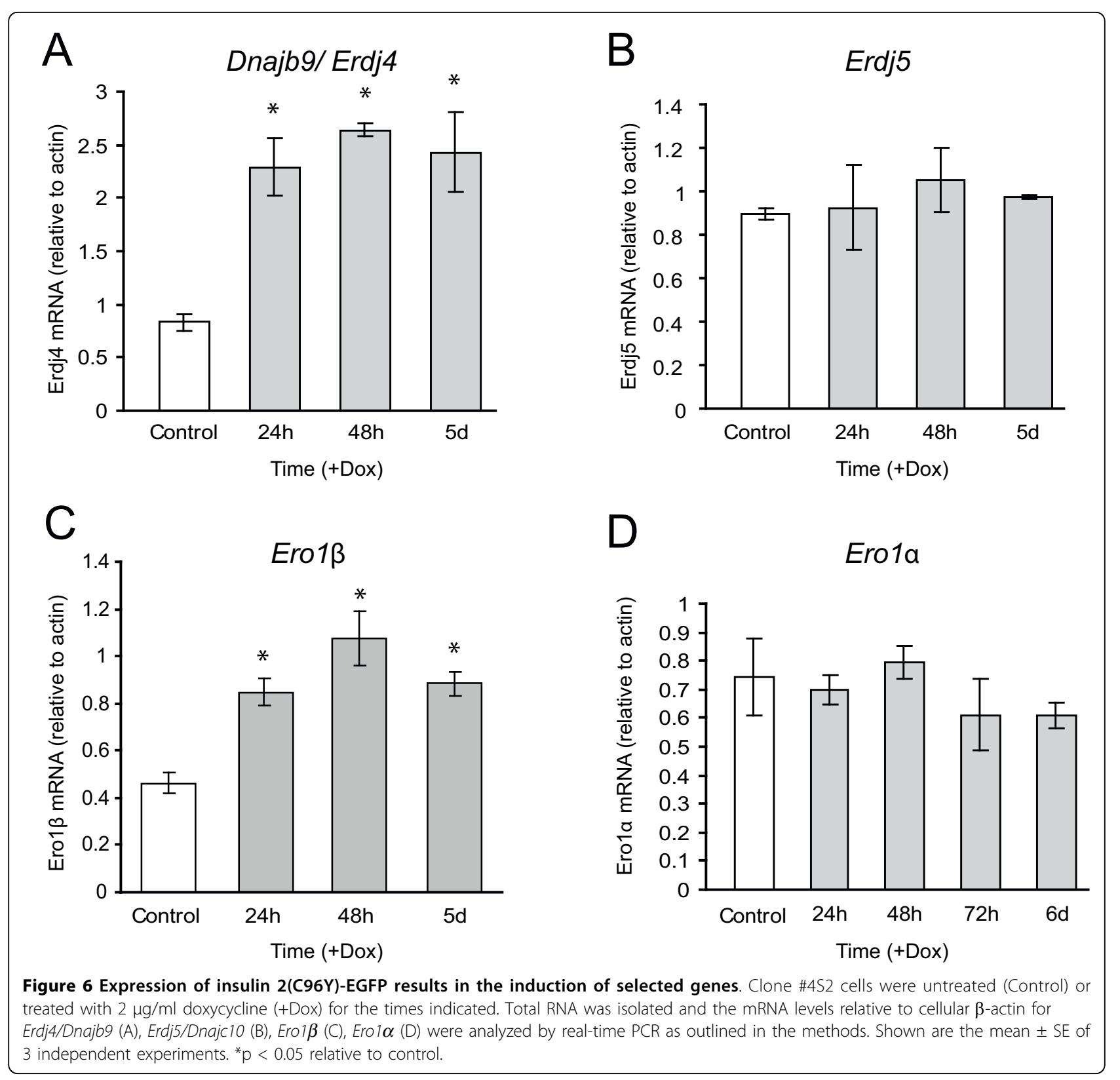

maintaining cell survival by degrading the misfolded insulin and preventing accumulation to toxic levels. We therefore examined whether inhibiting the ERAD system might sensitize the cells to cell death. As a first approach we inhibited proteasome function using lactacystin. Cells were induced with doxycycline for $48 \mathrm{~h}$ then treated or not with lactacystin and cell apoptosis was monitored. Inhibition of the proteasome resulted in a significantly higher percentage of apoptotic cells in the population (Figure 8A). This was also accompanied by an increase in the cellular levels of ubiquinated proteins (Figure 8B, left panel) and an increase in the levels of Ins2 (C96Y)-EGFP fusion protein and degradation fragments (Figure $8 \mathrm{~B}$, right panel). These results suggest that inhibiting ERAD increases misfolded protein levels and enhances ER stress-induced apoptosis.

As an alternative approach for inhibiting ERAD we targeted the Herp protein which was found to be induced early by mutant insulin expression (Table 1 ). Herp has been implicated in ERAD of certain misfolded proteins [23], although whether it is required for misfolded insulin degradation has not been examined. We first confirmed that the Herp protein is induced in response to mutant insulin expression (Figure 9A). To perturb ERAD function, we blunted the induction of Herp expression using siRNA (Figure 9B, C). Reducing 


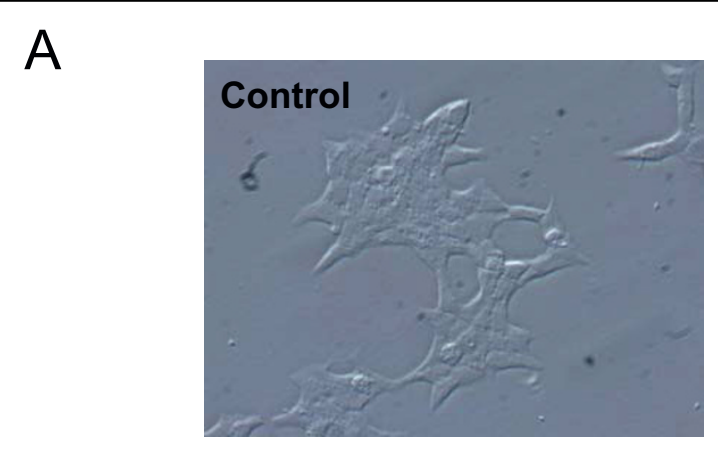

B

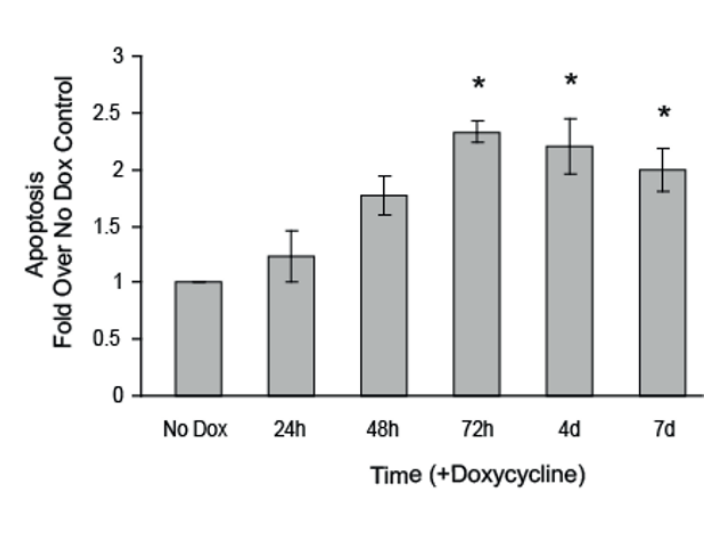

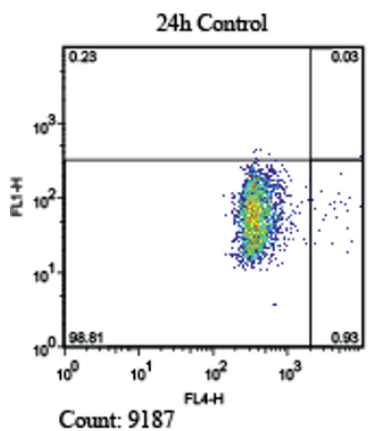

Count: 9187

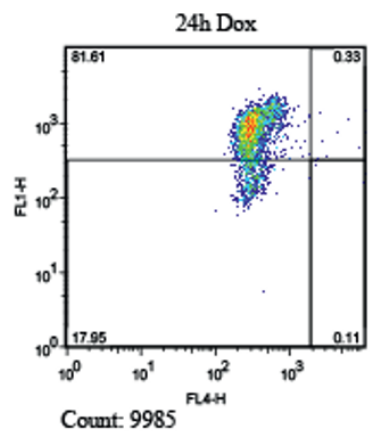

Count: 9985

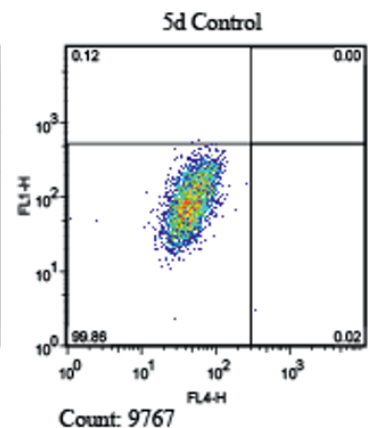

Count: 9767
C

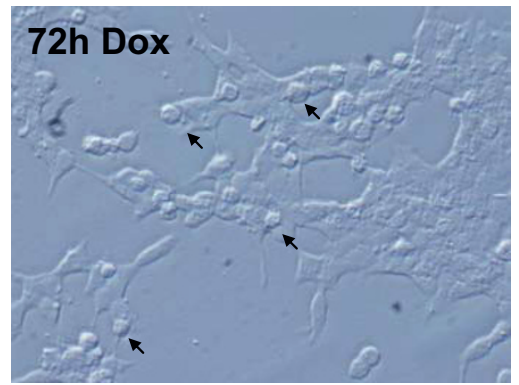

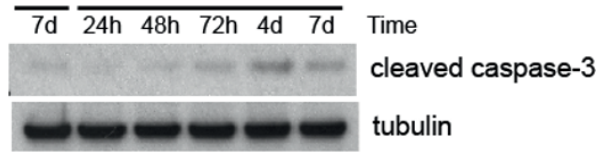

Figure 7 Expression of insulin 2 (C96Y)-EGFP induces apoptosis. A. Clone \#4S2 cells were treated or not with $2 \mu \mathrm{g} / \mathrm{ml}$ doxycycline for 72 h, fixed and imaged by differential interference contrast microscopy. Potentially apoptotic cells with a rounded morphology are indicated (arrows). B-D. Clone \#4S2 cells were treated with $2 \mu \mathrm{g} / \mathrm{ml}$ doxycycline for the indicated times. B. Following the treatments, the cells were lysed and apoptosis was measured using a cell death detection ELISA kit (Roche) as described in the methods. Shown are the mean \pm SE of 4 independent experiments. ${ }^{*} \mathrm{p}<0.05$. C. Cells were washed in PBS, lysed and equal amounts of protein were resolved by NuPAGE and immunoblotted using antibodies to cleaved caspase-3 and $\gamma$-tubulin. D. Cells were fixed and labeled with Alexa Fluor 647 dye-labeled anti-BrdU antibody. Cells were analyzed by flow cytometry; the FL1 laser excites GFP, whereas FL4 excites Fluor 647. Cells in the upper left and right quadrants were classified as mutant insulin expressing, cells in the upper and lower right quadrants were classified as apoptotic. The total number of cells examined is shown below each chart, and the percentage of cells in each quadrant is indicated.

Herp expression by about $40-50 \%$ resulted in an increase in the steady-state levels of the mutant insulin protein, even in the absence of doxycycline induction (Figure 9B). This also increased apoptosis levels in the population relative to control siRNA transfected cells (Figure 9D). With doxycyline induction for $48 \mathrm{~h}$ the levels of Ins2 (C96Y)-EGFP in Herp siRNA-treated cells was increased relative to control siRNA transfected cells, but the effect was small (Figure 9B). In some experiments we also observed a reduction in the degradation fragments in Herp siRNA-treated cells (see Figure 9B, Expt.\#2, low exposure), but this was not a consistent finding (Figure 9B, Expt.\#1). The inconsistent results may be due to the inefficient knock-down of the Herp protein achieved in these studies. Regardless, the levels of apoptosis in the population depleted of Herp 

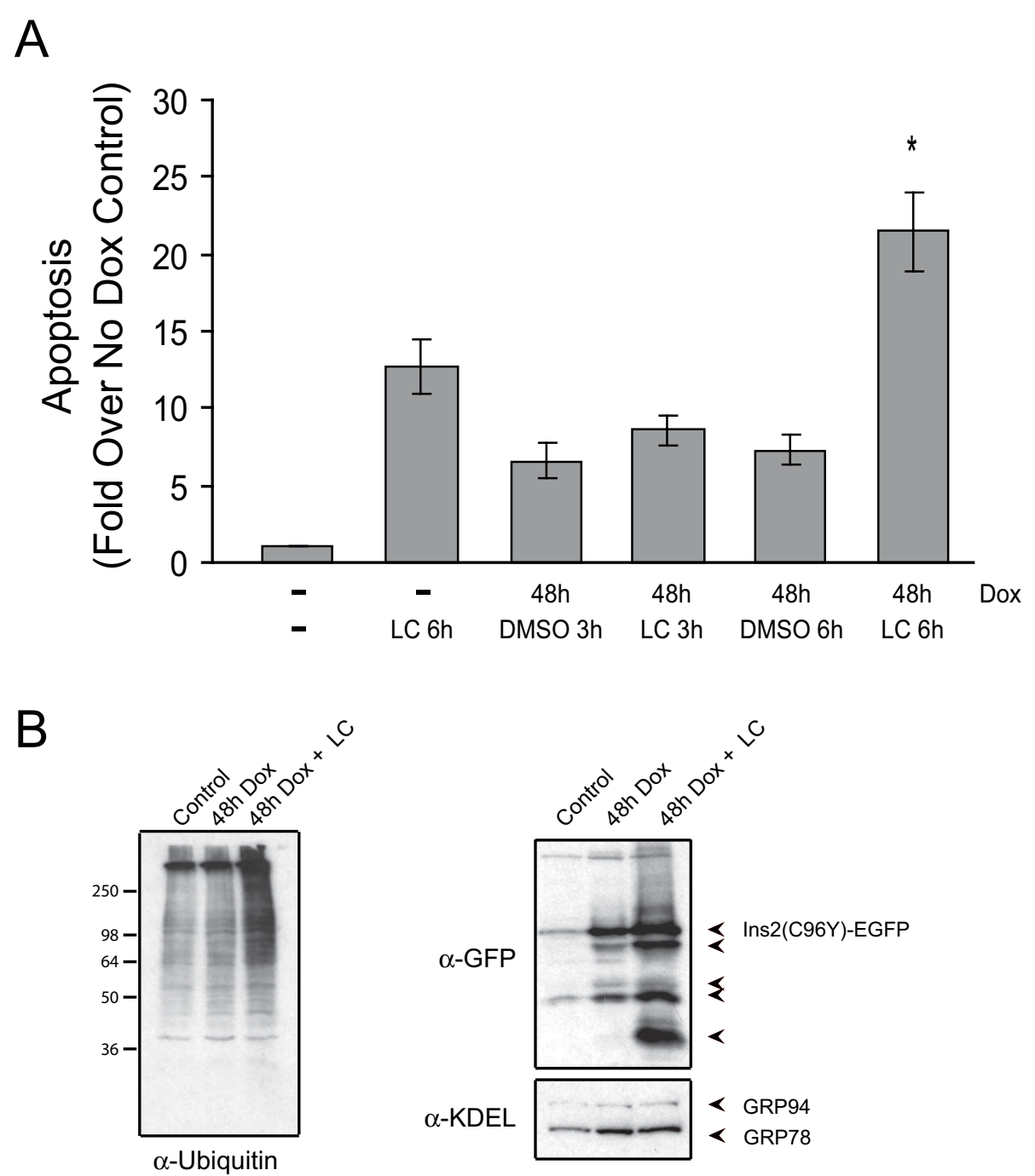

Figure 8 The proteasome inhibitor lactacystin increases susceptibility of the mutant insulin expressing clone to apoptosis. A. Clone \#4S2 cells were untreated or treated with $2 \mu \mathrm{g} / \mathrm{ml}$ doxycycline for $48 \mathrm{~h}$. Cells were then untreated or treated with $10 \mu \mathrm{M}$ of lactacystin (LC) or an equivalent volume of DMSO for the times indicated. Apoptosis was measured using a cell death detection ELISA kit as described in the Methods. Shown are the mean \pm SE of 3 independent experiments. ${ }^{*} p<0.05$. B. Following $42 \mathrm{~h}$ of doxycycline treatment, cells were untreated, or treated with $10 \mu \mathrm{M}$ of lactacystin (LC) or an equivalent volume of DMSO for $6 \mathrm{~h}$ in the presence of doxycycline. The cells were washed in PBS and lysed. Cell lysates (left panel) or TX-100 insoluble material (right panel) were resolved by SDS-PAGE and immunoblotted using the indicated antibodies. Note the increase in the levels of degradation products detected by the GFP antibody with LC treatment (arrowheads).

expression was significantly higher compared to control siRNA-transfected cells as measured by cleaved caspase 3 levels (Figure 9E). Altogether, these results suggest that the mutant insulin is an ERAD target and that Herp function is required for its degradation and that reducing Herp levels increases mutant insulin levels and sensitizes the cells to apoptosis.

\section{Discussion}

The UPR is an essential process by which cells respond to the accumulation of misfolded protein in the ER. This can occur either physiologically, as a result of acute secretory protein load, or as a result of pathological insults that may impede protein folding capacity. The basic ER stress response is well established involving an acute translational attenuation followed by the upregulation of a transcriptional profile that includes ER chaperone genes, ERAD components, protein transport genes, among others [2]. However, it is probable that different cell types have a unique profile of upregulated genes that are dependent on a particular cells function and the secretory proteins it produces. The goal of the present study was to examine the ER stress response in the insulin producing pancreatic $\beta$-cell. To do this we 


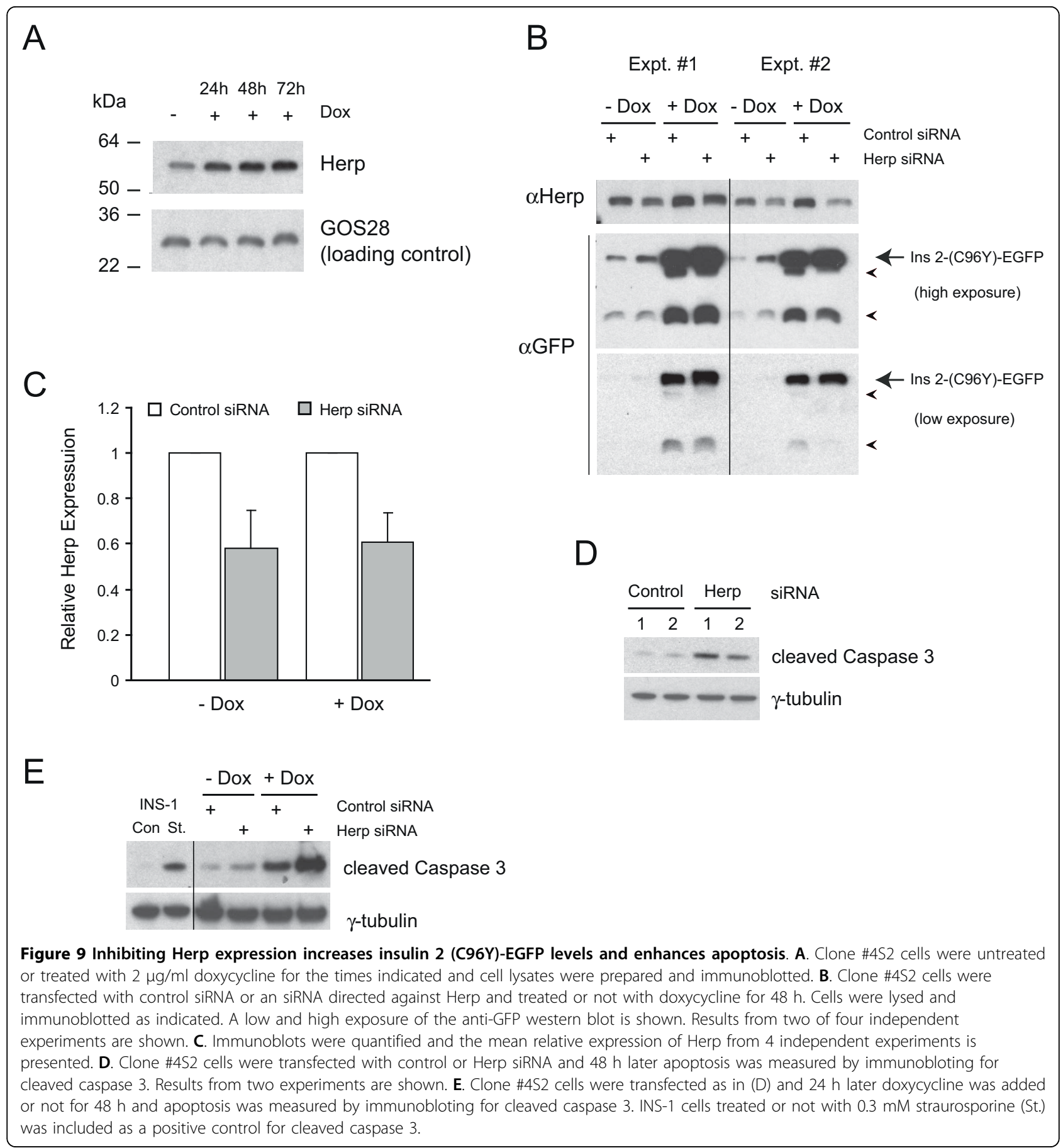

developed a pancreatic $\beta$-cell culture model with inducible expression of a folding-deficient insulin fusion protein based on the proinsulin mutation found in the Akita mouse [9]. The rationale behind this approach was that regulated expression of a single misfolded protein would allow for a temporal characterization of the UPR in $\beta$-cells. This may reflect the ER stress response to physiological conditions (acute insulin synthesis) and potentially a chronic response induced by pathological conditions occurring in type 2 diabetes (chronic insulin biosynthetic demands coupled with the effects of chronic free fatty acids, glucose and cytokines that induce ER stress).

Using the tetracycline/doxycycline-regulated expression system we created a double stable INS-1 cell clone with stable integration of the pTet-ON regulatory 
plasmid and the Ins2 (C96Y)-EGFP plasmid driven by the Tet/Dox-responsive promoter. The EGFP tag was used in order to facilitate selection of stable clones, as well as for sorting of the positive clones for cells with high expression of the Ins2 (C96Y)-EGFP fusion protein. In the clone selected for the studies basal expression of the mutant insulin is low, although detectable. Following doxycyline addition the mutant insulin is markedly induced by $24 \mathrm{~h}$, reaching maximal expression by $\sim 72 \mathrm{~h}$ and expression is maintained for several days. Expression of the mutant insulin fusion protein leads to a swollen ER lumen that is readily detectable in many cells and is indicative of misfolded protein accumulation and a stressed ER. This result is similar to the phenotype observed in the $\beta$-cells of Akita mice [9]. As expected, expression of folding-deficient Ins 2 (C96Y)EGFP fusion protein resulted in the induction of UPR pathways (PERK, IRE1 and ATF6).

To analyze the ER stress response in the cell line we performed microarray expression profiling and real time PCR analysis at various times following mutant protein expression. We chose time-points of Ins2 (C96Y)-EGFP expression when no significant apoptosis was observed $(24 \mathrm{~h})$ and longer expression time points (48 h and 5 days), when apoptotic cell death was detectable. After $24 \mathrm{~h}, 45$ genes were induced, while the number of induced genes was substantially increased after $72 \mathrm{~h}$ (86) and 5 days (68). Interestingly, the number of downregulated genes was also increased at the longer incubation times (37 and 56 after $48 \mathrm{~h}$ and $5 \mathrm{~d}$ of doxycycline induction, respectively). This may reflect the observation that prolonged activation of IRE1 $\alpha$ can result in relaxed specificity and cleavage of cellular mRNAs [24], resulting in the downregulation of some genes as a result of prolonged ER stress.

After $24 \mathrm{~h}$ of Ins2 (C96Y)-EGFP expression the most consistently induced genes were ER resident chaperones and co-chaperones (Grp78, Erdj4, P58 ${ }^{I P K}, \operatorname{Erdj} 3$, Fkbp11) and an ERAD component (Herp). The J-domain containing co-chaperones (Erdj4, P58 $8^{I P K}$ ) have been shown to be induced by ER stress in various cell types [20,25-32]. Recently, P58 ${ }^{\mathrm{IPK}}$ and ERdj3 have been found to interact with misfolded proteins in the ER prior to recruitment of the chaperone GRP78 [26,29,30,32]. In addition, these proteins have also been implicated in targeting misfolded proteins for degradation via the ERAD system $[20,28]$. Thus, expression of misfolded insulin causes the induction of chaperone proteins early in an effort to fold the mutant insulin. These chaperones are maintained at high levels throughout the time course of mutant insulin induction and some may assist in degradation of the misfolded molecule once folding is found to be futile (discussed below). The importance of P58 ${ }^{\mathrm{IPK}}$ function in normal pancreatic $\beta$-cells in vivo is evidenced by increased pancreatic $\beta$-cell apoptosis and hyperglycemia in knock-out mice [33]. However, the detailed molecular function of these co-chaperones in $\beta$ cells has not been examined to date.

Interestingly, although there are six mammalian DNAJ domain-containing proteins, we only found a subset to be induced by mutant insulin expression. Notable among those that were not upregulated is ERdj5. Recently, expression of a folding-deficient version of the secreted protein surfactant protein C in HEK293 cells caused the induction of various ER stress response genes, including Erdj4 and Erdj5, which were shown to be required for degradation of the folding-deficient surfactant protein C [20]. Surfactant protein C, like proinsulin, contains disulfide bonds, but is not glycosylated. Thus, it is interesting that we do not observe induction of Erdj5 in $\beta$-cells expressing folding-deficient proinsulin. A recent report, however, has shown that ERdj5 can interact with EDEM proteins and is required for reducing disulfide bonds on misfolded, glycosylated proteins prior to retrotranslocation [21]. EDEM genes were not detected in the microarray analysis, suggesting that proinsulin may not require EDEM or ERdj5 for its degradation.

Comparing the UPR response observed in our study to ER stress responses in other cell types shows that some of the early chaperone genes induced by mutant protein expression are not observed in other systems. For example, tunicamycin treatment of neuroblastoma cells [34] or expression of a retroviral protein in astrocytes, which induces ER stress [35], did not cause an upregulation of Erdj4, $P 58^{I P K}$, Erdj3, or Fkbp11. Importantly, all of these genes have been shown to be induced by ER stress caused by prolonged palmitate exposure in cultured mouse MIN6 cells [36]. Saturated FFAs have been shown to induce ER stress in pancreatic $\beta$-cells and this may contribute to $\beta$-cell dysfunction $[15,36,37]$. In addition, a recent proteomic study examining islets from a diabetic insulin resistant mouse model has shown that the protein (and mRNA levels) of some of these (P58 ${ }^{\mathrm{IPK}}$, ERdj3, Fkbp11) are upregulated [38]. Thus, the induction of these genes/proteins are likely important cell protective ER stress response proteins in $\beta$-cells and a detailed biochemical analysis of their function in mediating proinsulin folding and/or degradation is warranted.

In addition to ER chaperone genes and ERAD components, several other genes were found to be induced early as a result of Ins2 (C96Y)-EGFP expression, including Sdf2l1, Armet and Creld2. All three were abundantly upregulated at both early and late time points. The exact functions of the protein products of these genes in the ER stress response is largely undefined, although these proteins have also been reported 
to be induced by ER stress-inducing compounds such as tunicamycin in other cell types [39-41].

The appearance of prominent lower migrating bands recognized by anti-GFP antibodies indicates that the Ins2 (C96Y)-EGFP fusion protein is being degraded. Similar cleavage products have been detected with wildtype proinsulin tagged with GFP at the C-terminus and was suggested to occur from non-specific cleavage of the fusion protein at some point along the secretory pathway [42]. In the case of the Ins2 (C96Y)-EGFP the cleavage products are not efficiently immunoprecipitated by anti-GFP antibodies and are not detected in ER fractions. Thus, the smaller migrating bands recognized by GFP antibodies are likely degradation products of proteolysis occurring in the cytoplasm. The full-length mutant insulin fusion protein appears to be inaccessible to the secretory pathway and is retained in the ER, which is consistent with a report showing that the C96Y mutation in proinsulin results in misfolding of the molecule and retention in the ER [42].

The Ins2 (C96Y)-EGFP fusion protein is likely degraded by the ubiquitin-dependent ERAD system. The ERAD-associated genes Herp and Sel1 were induced by mutant insulin expression, which is consistent with the finding that Sel1 is upregulated in Akita islets [43]. Inhibiting the $26 \mathrm{~S}$ proteasome resulted in an increase in the levels of Ins2 (C96Y)-EGFP and sensitized the cells to cell death. This was also the effect observed by reducing Herp expression using siRNA, a protein recently shown to be required for the degradation of a disulfide bondcontaining mutant version of the kappa light chain [23]. The process of Ins2 (C96Y)-EGFP degradation however, may be quite complex. If the proteasome was responsible for generating the degradation fragments observed (Figure 2) than inhibiting the proteasome would be expected to not affect the steady-state levels of these fragments; new fragments would be prevented from being generated from Ins2 (C96Y)-EGFP and fragments already present prevented from being degraded. However, most degradation fragments were actually increased by proteasome inhibition (Figure 8B), suggesting that other proteases may be responsible for generating the degradation fragments that are then targeted for ubiquitin-dependent degradation.

It should be pointed out that although expression of the Ins2 (C96Y)-EGFP fusion protein induces ER stress and degradation of the fusion protein, due to the presence of the EGFP tag the degradation of the fusion construct may not be identical to the degradation of untagged proinsulin C96Y. Furthermore, it is possible that the ER stress response elicited by untagged proinsulin C96Y is different compared to that of Ins2 (C96Y)-EGFP. These possibilities should be explored in future studies.
This model system also allowed us to examine potential gene expression changes associated with ER stress-induced cell death. An upregulation of the proapoptotic transcription factor Chop and one of its target genes (Trib3) was evident by $24 \mathrm{~h}$ of Ins2 (C96Y)EGFP expression, which is indicative of PERK pathway activation and is likely to be a normal physiological response. At this time point no significant apoptosis is detected in the population. After $48 \mathrm{~h}$ of mutant insulin expression however, the levels of Chop and Trib3 were even higher, which coincided with detection of apoptosis in the population. Thus, a sustained increase in the levels of CHOP and TRIB3 proteins may tilt cells towards apoptosis induction. Pancreatic $\beta$-cells of CHOP-deficient heterozygous Akita mice are partially protected from cell death [12], although clearly there are other factors also involved. In the mutant insulin expressing cell line the most highly induced gene after $48 \mathrm{~h}$ was Trib3. Recently, the TRIB3 protein has been shown to be induced by the PERK-ATF4-CHOP pathway and has been implicated in mediating apoptosis $[18,19]$ and in hyperglycemia-induced pancreatic $\beta$-cell death [44]. The mechanism of this effect, however, is unclear. Whether the TRIB3 protein is responsible for apoptosis induction and how much of the apoptosis is TRIB3-dependent in this model system requires future study.

Despite the abundant upregulation of Chop and Trib3 in response to mutant insulin expression, the level of apoptotic cells in the population remained rather low, even after long term expression of the mutant construct. This is likely because one of the main cell protective effects induced by the UPR, ERAD, is also upregulated. Inhibition of ERAD by inhibiting the cytosolic proteasome or inhibiting Herp upregulation sensitizes the cells to apoptosis, supporting the notion that the ERAD pathway may support cell survival by degradation of misfolded insulin.

\section{Conclusions}

The $\beta$-cell model of ER stress described in this study has allowed for a detailed characterization of the ER stress response induced by misfolded Ins2 (C96Y)EGFP expression and for the identification of both cell protective and possible cell destructive genes. The repertoire of genes/proteins induced is unique to this cell type compared to the UPR induced in other cell types, perhaps reflecting the unique role of $\beta$-cells to produce insulin. The Herp protein and ER-associated degradation is essential for maintaining cell survival in cells expressing mutant insulin. The cell model developed here will be useful in studies examining the function of ER stress-induced genes. 


\section{Additional material}

Additional file 1: This file lists all the genes whose expressed increased or decreased $\mathbf{>} \mathbf{2}$-fold in at least two of three independent experiments. Excel file presenting all of the Affymetrix probes whose expression was increased or decreased by at least 2 fold between doxycycline-treated vs. control, untreated INS-1 clone \#4S2 cells. Data from 3 independent experiments ( $N=1, N=2, N=3$ ) for all doxycycline treatment time points ( $24 \mathrm{~h}, 48 \mathrm{~h}$, and 5 days) is shown. Note that gene descriptions for these tables are provided by the GeneSpring software. Bold indicates probes whose expression was changed in all three experiments, while regular font indicates genes that were changed in at least 2 of 3 independent experiments. The primary data files for the microarray experiments have been deposited in the Gene Expression Omnibus (GEO) database (GSE22537).

Additional file 2: This file lists the well substantiated genes whose expressed increased or decreased $>\mathbf{2}$-fold in at least two of three independent experiments. Excel file presents expression data for well substantiated genes derived from the data presented in additional file 1. The putative function of the genes is derived from the NCBI database. Data from 3 independent experiments for all doxycycline treatment time points is provided.

\section{Acknowledgements}

We thank Dr. Claes Wollheim, University of Geneva for providing the insulinoma cell line INS-1, Dr. Seiichi Oyadomari for providing the insulinEGFP plasmid, Dr. Linda Hendershot for the anti-Herp antibody and Dr. Jonathon Rocheleau for help with Image J fluorescence intensity quantitation. We thank Monika Sharma at the UHN microarray facility for the microarray analysis. This work was supported, in part, by operating grants to A.V. from the Canadian Diabetes Association (GA-2-06-2138-AV) and from the Canadian Institutes for Health Research (86641). Infrastructure support for the A.V. laboratory was provided by funding from the Canadian Foundation for Innovation and the Ontario Innovation Trust. AV is the recipient of a Tier II Canada Research Chair award. TH, MS and EL were supported in part by Banting and Best Diabetes Centre (University of Toronto) graduate studentships. TT was supported by a graduate studentship from NSERC.

\section{Author details}

${ }^{1}$ Division of Cellular and Molecular Biology, Toronto General Research Institute, University Health Network, 101 College Street, TMDT 10-706, Toronto, M5G 1L7, Canada. ${ }^{2}$ Department of Biochemistry, University of Toronto, 1 King's College Circle, Medical Sciences Building 5th Floor, Toronto, M5S 1A8, Canada. ${ }^{3}$ Department of Physiology, University of Toronto, 1 King's College Circle, Medical Sciences Building 3rd Floor, Toronto, M5S 1A8, Canada. ${ }^{4}$ University Health Network, 101 College Street, TMDT 10-706, Toronto, M5G 1L7, Canada.

\section{Authors' contributions}

TH was responsible for apoptosis analysis and the real-time PCR and microarray studies. EL was responsible for generating the mutant insulin expressing cell line and some of the studies examining the ER stress response. MS contributed experiments reported in Figure 9. $\Pi T$ and $L Z$ contributed experiments reported in Figure 4. All authors made substantial contributions to the design of the experiments, acquisition and analysis of data and preparation of the figures. AV supervised these studies and prepared the manuscript. All authors read and approved the final manuscript.

\section{Competing interests}

The authors declare that they have no competing interests.

Received: 11 November 2009 Accepted: 26 July 2010

Published: 26 July 2010

\section{References}

1. Ren J, Jin P, Wang E, Liu E, Harlan DM, Li X, Stroncek DF: Pancreatic islet cell therapy for type I diabetes: understanding the effects of glucose stimulation on islets in order to produce better islets for transplantation. J Transl Med 2007, 5.

2. Ron D, Walter P: Signal integration in the endoplasmic reticulum unfolded protein response. Nat Rev Mol Cell Biol 2007, 8:519-529.

3. Eizirik DL, Cardozo AK, Cnop M: The role for endoplasmic reticulum stress in diabetes mellitus. Endocr Rev 2008, 29:42-61.

4. Oyadomari S, Mori M: Roles of CHOP/GADD153 in endoplasmic reticulum stress. Cell Death and Diff 2004, 11:381-389.

5. Harding HP, Zeng $H$, Zhang $Y$, Jungries $R$, Chung P, Plesken $H$, Sabatini DD, Ron D: Diabetes Mellitus and exocrine pancreatic dysfunction in Perk-/mice reveals a role for translational control in secretory cell survival. $\mathrm{Mol}$ Cell 2001, 7:1153-1163.

6. Scheuner D, Vander Mierde D, Song B, Flamez D, Creemers JWM, Tsukamoto K, Ribick M, Schuit FC, Kaufman RJ: Control of mRNA translation preserves endoplasmic reticulum function in beta cells and maintains glucose homeostasis. Nature Med 2005, 11:757-764.

7. Zhang P, McGrath B, Li S, Frank A, Zambito F, Reinert J, Gannon M, Ma K, McNaughton K, Cavener DR: The PERK eukaryotic initiation factor 2 alpha kinase is required for the development of the skeletal system, postnatal growth, and the function and viability of the pancreas. Mol Cell Biol 2002 22:3864-3874.

8. Delepine M, Nicolino M, Barrett T, Golamaully M, Lathrop GM, Julier C EIF2AK3, encoding translation initiation factor 2-alpha kinase 3, is mutated in patients with Wolcott-Rallison syndrome. Nat Genet 2000 25:406-409.

9. Wang J, Takeuchi T, Tanaka S, Kubo S-K, Kayo T, Lu D, Takata K, Koizumi A, Izumi T: A mutation in the insulin 2 gene induces diabetes with severe pancreatic beta-cell dysfunction in the Mody mouse. J Clin Invest 1999, 103:27-37.

10. Yoshioka M, Kayo T, Ikeda T, Koizumi A: A novel locus, Mody4, distal to D7Mit189 on chromosome 7 determines early-onset NIDDM in nonobese C57BL/6 (Akita) mutant mice. Diabetes 1997, 46:887-894.

11. Ahren B: Type 2 diabetes, insulin secretion and beta-cell mass. Curr $\mathrm{Mol}$ Med 2005, 5:275-286.

12. Oyadomari S, Koizumi A, Takata K, Gotoh T, Akira S, Araki E, Mori M: Targeted disruption of the Chop gene delays endoplasmic reticulum stress-mediated diabetes. J Clin Invest 2002, 109:525-532.

13. Asfari M, Janjic D, Meda P, Li G, Halban PA, Wollheim CB: Establishment of 2-mercaptoethanol-dependent differentiated insulin-secreting cell lines. Endocrinology 1992, 130:167-178.

14. Zhang L, Lai E, Teodoro T, Volchuk A: GRP78, but not protein-disulfide isomerase, partially reverses hyperglycemia-induced inhibition of insulin synthesis and secretion in pancreatic beta-cells. J Biol Chem 2009, 284:5289-5298.

15. Karaskov E, Scott C, Zhang L, Teodoro T, Ravazzola M, Volchuk A: Chronic palmitate but not oleate exposure induces endoplasmic reticulum stress which may contribute to INS-1 pancreatic beta-cell apoptosis. Endocrinology 2006, 147:3398-3407.

16. Reetz A, Solimena M, Matteoli M, Folli F, Takei K, De Camilli P: GABA and pancreatic beta-cells: colocalization of glutamic acid decarboxylase (GAD) and GABA with synaptic-like microvesicles suggests their role in GABA storage and secretion. EMBO J 1991, 10:1275-1284.

17. Lai E, Bikopoulos G, Wheeler MB, Rozakis-Adcock M, Volchuk A: Differential activation of ER stress and apoptosis in response to chronically elevated free fatty acids in pancreatic beta-cells. Am J Physiol Endocrinol Metab 2008, 294:E540-E550

18. Ohoka N, Yoshii S, Hattori T, Onozaki K, Hayashi H: TRB3, a novel ER stressinducible gene, is induced via ATF4-CHOP pathway and is involved in cell death. EMBO J 2005, 24:1243-1255.

19. Hegedus Z, Czibula A, Kiss-Toth E: Tribbles: a family of kinase-like proteins with potent signalling regulatory function. Cell Sig 2007, 19:238-250.

20. Dong M, Bridges JP, Apsley $K, X u Y$, Weaver TE: ERdj4 and ERdj5 are required for endoplasmic reticulum-associated protein degradation of misfolded surfactant protein C. Mol Biol Cell 2008, 19:2620-2630.

21. Ushioda R, Hoseki J, Araki K, Jansen G, Thomas DY, Nagata K: ERdj5 is required as a disulfide reductase for degradation of misfolded proteins in the ER. Science 2008, 321:569-572. 
22. Pagani M, Fabbri M, Benedetti C, Fassio A, Pilati S, Bulleid NJ, Cabibbo A Sitia R: Endoplasmic reticulum oxidoreductin 1-beta (ERO1-Lbeta), a human gene induced in the course of the unfolded protein response. $J$ Biol Chem 2000, 275:23685-23692.

23. Okuda-Shimizu Y, Hendershot LM: Characterization of an ERAD pathway for nonglycosylated BiP substrates, which require Herp. Mol Cell 2007, 28:544-554.

24. Han D, Lerner AG, Vande Walle L, Upton J-P, Xu W, Hagen A, Backes BJ, Oakes SA, Papa FR: IRE1alpha kinase activation modes control alternate endoribonuclease outputs to determine divergent cell fates. Cell 2009, 138:562-575.

25. Cheetham ME, Caplan AJ: Structure, function and evolution of DnaJ: conservation and adaptation of chaperone function. Cell Stress Chaperones 1998, 3:28-36.

26. Jin Y, Awad W, Petrova K, Hendershot LM: Regulated release of ERdj3 from unfolded proteins by BiP. EMBO J 2008, 27:2873-2882.

27. Kurisu J, Honma A, Miyajima H, Kondo S, Okumura M, Imaizumi K: MDG1/ ERdj4, an ER-resident DnaJ family member, suppresses cell death induced by ER stress. Genes Cells 2003, 8:189-202.

28. Oyadomari S, Yun C, Fisher EA, Kreglinger N, Kreibich G, Oyadomari M, Harding HP, Goodman AG, Harant H, Garrison JL, et al: Cotranslocational degradation protects the stressed endoplasmic reticulum from protein overload. Cell 2006, 126:727-739.

29. Petrova K, Oyadomari S, Hendershot LM, Ron D: Regulated association of misfolded endoplasmic reticulum lumenal proteins with P58/DNAJc3. EMBO J 2008, 27:2862-2872.

30. Rutkowski DT, Kang S-W, Goodman AG, Garrison JL, Taunton J, Katze MG, Kaufman RJ, Hegde RS: The role of p58IPK in protecting the stressed endoplasmic reticulum. Mol Biol Cell 2007, 18:3681-3691.

31. Shen Y, Hendershot LM: ERdj3, a stress-inducible endoplasmic reticulum DnaJ homologue, serves as a cofactor for BiP's interactions with unfolded proteins. Mol Biol Cell 2005, 16:40-50.

32. Shen $Y$, Meunier $L$, Hendershot LM: Identification and characterization of a novel endoplasmic reticulum (ER) DnaJ homologue, which stimulates ATPase activity of BiP in vitro and is induced by ER stress. $J$ Biol Chem 2002, 277:15947-15956

33. Ladiges WC, Knoblaugh SE, Morton JF, Korth MJ, Sopher BL, Baskin CR, MacAuley A, Goodman AG, LeBoeuf RC, Katze MG: Pancreatic beta-cell failure and diabetes in mice with a deletion mutation of the endoplasmic reticulum molecular chaperone gene P58IPK. Diabetes 2005, 54:1074-1081.

34. Reimertz C, Kogel D, Rami A, Chittenden T, Prehn JHM: Gene expression during ER stress-induced apoptosis in neurons: induction of the $\mathrm{BH} 3-$ only protein Bbc3/PUMA and activation of the mitochondrial apoptosis pathway. J Cell Biol 2003, 162:587-597.

35. Antony JM, Ellestad KK, Hammond R, Imaizumi K, Mallet F, Warren KG, Power $C$ : The human endogenous retrovirus envelope glycoprotein, syncytin-1, regulates neuroinflammation and its receptor expression in multiple sclerosis: a role for endoplasmic reticulum chaperones in astrocytes. J Immunol 2007, 179:1210-1224.

36. Laybutt DR, Preston AM, Akerfeldt MC, Kench JG, Busch AK, Biankin AV, Biden TJ: Endoplasmic reticulum stress contributes to beta cell apoptosis in type 2 diabetes. Diabetologia 2007, 50:752-763.

37. Kharroubi I, Ladriere L, Cardozo AK, Dogusan Z, Cnop M, Eizirik DL: Free fatty acids and cytokines induce pancreatic beta-cell apoptosis by different mechanisms: role of nuclear factor-kappaB and endoplasmic reticulum stress. Endocrinology 2004, 145:5087-5096.

38. Lu H, Yang Y, Allister EM, Wijesekara N, Wheeler MB: The identification of potential factors associated with the development of type 2 diabetes. Mol Cell Prot 2008, 7:1434-1451.

39. Apostolou A, Shen Y, Liang Y, Luo J, Fang S: Armet, a UPR-upregulated protein, inhibits cell proliferation and ER stress-induced cell death. Exper Cell Resear 2008, 314:2454-2467.

40. Fukuda S, Sumii M, Masuda Y, Takahashi M, Koike N, Teishima J, Yasumoto H, Itamoto T, Asahara T, Dohi K, et al: Murine and human SDF2L1 is an endoplsmic reticulum stress-inducible gene and encodes a new member of the Pmt/rt protein family. Biochem Biophys Resear Commun 2001, 280:407-414.

41. Wu J, Rutkowski DT, Dubois M, Swathirajan J, Saunders T, Wang J, Song B, Yau GD-Y, Kaufman RJ: ATF6alpha optimizes long-term endoplasmic reticulum function to protect cells from chronic stress. Dev Cell 2007, 13:351-364.

42. Liu M, Hodish I, Rhodes CJ, Arvan P: Proinsulin maturation, misfolding, and proteotoxicity. Proc Natl Acad Sci USA 2007, 104:15841-15846.

43. Allen JR, Nguyen LX, Sargent KE, Lipson KL, Hackett A, Urano F: High ER stress in $\beta$-cells stimulates intracellular degradation of misfolded insulin. Biochem Biophys Res Commun 2004, 324:166-170.

44. Qian B, Wang H, Men X, Zhang W, Cai H, Xu S, Xu Y, Ye L, Wollheim CB, Lou J: TRIB3 is implicated in glucotoxicity and oestrogen receptor stressinduced beta-cell apoptosis. J Endocrinol 2008, 199:407-416.

doi:10.1186/1471-2121-11-59

Cite this article as: Hartley et al:: Endoplasmic reticulum stress response in an INS-1 pancreatic $\beta$-cell line with inducible expression of a foldingdeficient proinsulin. BMC Cell Biology 2010 11:59.

\section{Submit your next manuscript to BioMed Central and take full advantage of:}

- Convenient online submission

- Thorough peer review

- No space constraints or color figure charges

- Immediate publication on acceptance

- Inclusion in PubMed, CAS, Scopus and Google Scholar

- Research which is freely available for redistribution

Submit your manuscript at www.biomedcentral.com/submit
C Biomed Central 